\title{
Comment to the article "How to measure and report the capacity of electrochemical double layers, supercapacitors, and their electrode materials" [1]
}

\author{
Genady Ragoisha ${ }^{1} \cdot$ Yauhen Aniskevich ${ }^{2}$ \\ Received: 9 November 2020 / Revised: 9 November 2020 / Accepted: 16 November 2020 / Published online: 7 January 2021 \\ (C) Springer-Verlag GmbH Germany, part of Springer Nature 2021
}

The recently published article [1] contains the following statement about our publication [2] (the reference numbers in the citation are adjusted to the list presented below this comment):

"The confusion between Faradaic, capacitive, and pseudocapacitive behavior/current response of electrode materials has been addressed also by Ragoisha and Aniskevich [2] by repeating previous arguments already collected in [3] without adding new arguments or considerations."

In fact: no argument from [3] was repeated in [2], as [2] was submitted and published online in April 2016, while [3] was submitted in September 2016 and published online in December 2016. We hereby present a Web link to "False capacitance of supercapacitors", missing in [1], to facilitate the unbiased comparison of actual arguments of both works by readers of Journal of Solid State Electrochemistry.

\section{References}

1. Ge Y, Xie X, Roscher J, Holze R, Qu Q (2020) How to measure and report the capacity of electrochemical double layers, supercapacitors, and their electrode materials. J Solid State Electrochem 24(11-12): 3215-3230

2. Ragoisha GA, Aniskevich YM (2016) False capacitance of supercapacitors, arXiv:1604.08154. https://arxiv.org/abs/1604. 08154

3. Holze R (2017) From current peaks to waves and capacitive currentson the origins of capacitor-like electrode behavior. J Solid State Electrochem 21(9):2601-2607

Publisher's note Springer Nature remains neutral with regard to jurisdictional claims in published maps and institutional affiliations.
Genady Ragoisha

ragoisha@yahoo.com

1 Research Institute for Physical Chemical Problems, Belarusian State University, 220006 Minsk, Belarus

2 Belarusian State University, Nezalezhnastsi Av. 4, 220030 Minsk, Belarus 